\title{
Characterization of Various Biomass Feedstock Suitable for Small-Scale Energy Plants as Preliminary Activity of Biocheaper Project
}

\author{
Gianluca Cavalaglio ${ }^{1}{ }^{\circledR}$, Franco Cotana ${ }^{1}$, Andrea Nicolini ${ }^{1}{ }^{1}$, Valentina Coccia ${ }^{1}$, \\ Alessandro Petrozzi ${ }^{2}$, Alessandro Formica ${ }^{3}$ and Alessandro Bertini ${ }^{2, *}$ \\ 1 Department of Engineer, University of Perugia, via G. Duranti,63, 06125 Perugia, Italy; \\ cavalaglio@crbnet.it (G.C.); cotana@crbnet.it (F.C.); andrea.nicolini@unipg.it (A.N.); coccia@crbnet.it (V.C.) \\ 2 CIRIAF-CRB Section, University of Perugia, via G. Duranti,63, 06125 Perugia, Italy; petrozzi@crbnet.it \\ 3 Department for Innovation in Biological and AgroForestry Systems, University of Tuscia, via del paradiso \\ n.47, 01100 Viterbo, Italy; avv.alessandroformica@gmail.com \\ * Correspondence: bertini@crbnet.it
}

Received: 17 June 2020; Accepted: 11 August 2020; Published: 18 August 2020

\begin{abstract}
The PRIN (Research Project with Relevant National Interest) project "Biocheaper-biomasses circular holistic economy approach to energy equipments" started in September 2019 and involves several universities: Palermo as the university coordinator, Perugia, Cassino, Enna, Pavia and Bolzano. The main goal of the project is to increase the energy efficiency and reduce the pollutants emissions in small-scale biomass plant for energy (heat and power) production. The project focuses on residual lignocellulosic feedstocks from the agriculture and forestry sector, from energy crops in marginal lands and residues from rivers maintenance. Starting from the selection and characterization of potential feedstocks, the project aims at developing some prototypes for retrofit applications in existing biomass boilers, like a mini-cyclone for the reduction of particulate emissions and an exhaust air-water condensing system for the recovery of water and the reuse in agriculture. This work presents the first results of the project, in particular regarding the selection and the chemical-physical characterization of different biomass, available in different zones of Italy; in particular the authors investigated cardoon chips, carthamus chips, olive and wine pruning, residues from rivers maintenance. Each biomass sample was characterized in terms of moisture content, ashes content, volatile substances, fixed carbon, low and high heating value, content of carbon, nitrogen, hydrogen and main metals.
\end{abstract}

Keywords: biomass characterization; bioenergy; lignocellulosic residues

\section{Introduction}

The main target of the PRIN project "Biocheaper-biomasses circular holistic economy approach to energy equipments" is the study of sustainable solid-biomass energy pathways for small-size plants, in order to select the best technologies for the reduction of emissions and for the reuse of byproducts of the energy conversion processes (in agriculture and other sectors), in the perspective of a circular economy. In particular, the goal for this first stage is to select, collect and perform a physico-chemical characterization of local biomasses to be used for the overall purposes of the project. The use of lignocellulosic feedstocks and in particular the residues from agriculture and forestry sectors can reduce greenhouse gas emission and improve the environmental performance of bioenergy conversion systems. Also some energy crops, like cardoon and safflower, have a potential of growing since they are cultivated on the marginal lands and would not compete with conventional crops for food and feed [1,2]. A strategic sector that could significantly contribute to solid biomass supply is the maintenance of rivers to prevent hydrogeological and fire risk. Models have been developed for 
the management of the forest biomass growing in riverbeds, in order to achieve the objective of risk prevention and to plan the production of biomass available for bioenergy production [3].

The national legislation on waste management promotes the reuse of the forest biomass growing in the riverbeds which, according to article 183, paragraph 1, letter n, of Legislative Decree no. 152/2006, can be harvested for energy production in derogation of the waste management laws. The mentioned biomass, after being subjected to control operations functional to the recycling and the preparation for reuse, loses the qualification of urban waste (article 184, paragraph 2, letter d), of Legislative Decree no. 152/2006), and is not subjected to the provisions on the transport, treatment and disposal of waste provided [4]. The biomass in question can now be destined to energy plants for the production of bioenergy according to the UNI EN 17225-4 standard. The valorization of different biomasses for energy generation in different thermal and/or cogeneration/polygeneration plants, allow to improve energy efficiency and reduce the environmental impacts of selected sustainable solid biomasses supply chain [5].

The small-size biomass-based heating systems market, characterized by low energy efficiency and environmental performance, the use of different innovative technologies for the retrofitting of existing systems and the development of different strategic uses of biomasses (sustainable solid biomass residues to be used in different plant typologies) will help the downscaling of successful technologies to the scale of biomass systems and cover a relevant and specific technological need [6]. The advancement of knowledge gained by the use of these innovative technologies and practices will regard both energy efficiency, reduction of particulate through innovative techniques and environmental performances through the use of retrofit-oriented, easy-to-deploy and cost-effective technical solutions.

The paper investigated the characterization of biomass performances, either energetic, physical, and chemical of different biomass feedstocks: the lignocellulosic residues of cardoon energy crop, the prunings of grapevine and olive trees and the residues from the river maintenance (turkey oak). The choice of these biomasses was dictated by their great availability on the local territory, and for what concerns olive and vine prunings and turkey oak, they represent a residue of the agro-industrial supply chain and not a virgin resource $[7,8]$. Cardoon represents a more interesting energy crop, one that grows very well on the marginal lands of the Umbria region, has a low demand for water and does not compete with the food supply chain. This gives the preliminary information useful to further improving the average efficiency of different supply bioenergy pathways in Italy, having investigated the best physical and chemical conditions under which to perform the energy harvesting process [9].

The mentioned characterization is a relevant and preliminary phase of the project: the obtained results in terms of chemical, physical and energetic properties of such interesting resources for supplying small-size biomass plants and boilers constitute a useful database for the scientific community. Most of the articles in this research field focus on a specific biomass, while this paper provides a critical measurement-based comparison of different opportunities for small-size plants and boiler. This is to be considered the innovative aspect of the paper, which gives data also useful for the optimization of the working phases of the aforesaid plants.

\section{Materials and Methods}

\subsection{Biomass Sample Collection}

The biomasses employed in this work were collected from two regions of Italy, specifically Umbria and Sardegna. The residual, agro-industrial biomasses such as olive and grapevine prunings were collected from the private cultivation property of one of the authors of this article, which is located in Umbria, near the Perugia countryside, while the Turkey oak, deriving from the cleaning of the river banks, were harvested from the Umbrian section of Montecalvello ditch, a river section affected by cleaning operations of the riverbed and banks. Cardoon was instead kindly provided by Matrica S.p.A (Porto Torres, Sardegna). The amount of feedstock collected was between 5 and $10 \mathrm{~kg}$ in weight. 
Before performing the analyses, the biomasses were subjected to quartering in order to obtain a homogenous and representative sample.

The samples of olive and vine prunings are mainly composed of cut branches, while the cardoon sample comprises only the stems of the plant. The feedstocks were dried under atmospheric conditions over a period of a week. The dried samples were milled into a fine powder, with a particle average size of $200 \mu \mathrm{m}$ [10]. All experimental analyses were conducted in three replicates.

\subsection{Proximate and Ultimate Analysis}

Proximate analysis was carried out on each biomass to find out the amount of moisture, ash, volatile matter and fixed carbon of the analyzed samples. The analysis was carried out using a TGA-701 LECO thermogravimetric analyzer, in accord to the ASTM D 5142 protocol. A series of ceramic crucibles were weighed and then loaded with a maximum $5.0 \mathrm{~g}$ of powdered biomass sample. After placing the crucibles inside the instrument and closing the cover, the temperature is increased up to $900{ }^{\circ} \mathrm{C}$ under nitrogen atmosphere. The scope of ultimate analysis is to determine the percentage content of carbon, hydrogen and nitrogen of the biomass. The analyses were conducted with a TrueSpec CHN LECO elemental analyzer observing ASTM D5373 protocol for analysis and the results were expressed as dry basis of biomass [11].

The analyses were performed loading up to $0.05-0.1 \mathrm{~g}$ of sample into a pre-weighed tin capsule and then loaded into the $\mathrm{CHN}$ analyzer. The furnace was heated to $950{ }^{\circ} \mathrm{C}$ under a constant flow of helium and oxygen. Data were collected by the TrueSpec LECO software.

\subsection{Higher Heat Value Determination}

The higher heat value (HHV) was calculated from the elemental composition using the following [12] Equation (1):

$$
H H V=(35.5 \times \% C+142.3 \times \% H-15.4 \times \% O-14.5 \% N) \times 10^{-2}
$$

where $C, H, O, N$ are respectively carbon, hydrogen, oxygen and nitrogen composition percentages. The oxygen value was indirectly calculated by difference, assuming negligible sulfur content, using the following [12] Equation (2):

$$
\mathrm{O} \%=100 \%-a \operatorname{sh} \%-\mathrm{C} \%-H \%-N \%
$$

\subsection{Analysis of Micro- and Macro- Nutrients of the Biomass}

The analyses of micro- and macro- nutrients content of the biomass were conducted following UNI CEN/TS 15290:2006 protocol, using a Perkin-Elmer Optima 8000 ICP-OES Spectrophotometer [13]. The samples were first mineralized using a Milestone ETHOS ONE Microwave-assisted extractor (MAE) in order to fully oxidize all traces of organic components, leaving only the inorganic fraction of the biomass. Up to $500 \mathrm{mg}$ of sample were loaded inside the MAE vessel, to which was then added $9 \mathrm{~mL}$ of the oxidizing solution (8:1 mixture of $\mathrm{HNO}_{3}$ and $\mathrm{H}_{2} \mathrm{O}_{2}$ ). Mineralization was conducted at a temperature of $180^{\circ} \mathrm{C}$ with a heating ramp of $10 \mathrm{~min}$ and a hold time of $30 \mathrm{~min}$.

After mineralization, the resulting solution was diluted to $50 \mathrm{~mL}$ and analyzed at the ICP-OES. After calibrating the instrument using calibration and reagent blanks, which are the solvent in which the samples are dissolved and the mineralization solution, respectively, the following parameters were introduced: nebulizer flow, $0.70 \mathrm{~L} / \mathrm{min}$; radio frequency power, $1450 \mathrm{~W}$; sample introduction, $1.1 \mathrm{~mL} / \mathrm{min}$; flush time, $10 \mathrm{~s}$; delay time, $30 \mathrm{~s}$; read time, $5 \mathrm{~s}$; wash time, $50 \mathrm{~s}$; replicates, three (each sample read three times). Standards were prepared from 1000 ppm stock solutions and diluted with deionized water and later acidified with $67 \% \mathrm{HNO}_{3}$ in order to have a final, standard solution of metal in $10 \% \mathrm{HNO}_{3}$. 5-point calibration curves were registered for every analyzed metal. Table 1 shows the 
wavelengths selected for each metal. The amount of metal present in the biomass was reported in the Table 1, expressed in parts per million (ppm) and all calculation were done by the analysis software.

Table 1. Wavelength selected for the reading the investigated metals.

\begin{tabular}{cc}
\hline Metal & Wavelength $(\mathbf{n m})$ \\
\hline $\mathrm{P}$ & 21.914 \\
$\mathrm{Mg}$ & 285.213 \\
$\mathrm{Na}$ & 589.592 \\
$\mathrm{~K}$ & 766.490 \\
$\mathrm{Ca}$ & 315.887 \\
$\mathrm{Fe}$ & 238.204 \\
$\mathrm{Cu}$ & 327.393 \\
$\mathrm{Al}$ & 308.215 \\
\hline
\end{tabular}

\subsection{Compositional Analysis}

All the biomasses used in this work were characterized in terms of cellulose, hemicellulose, acetyls, lignin and extractives content. The moisture of the samples was measured with a METTLER TOLEDO HB43-S halogen moisture analyzer, showing values equal to $2.14 \%$ of water content for grapevine pruning, $8.48 \%$ for olive pruning, $5.83 \%$ for turkey oak and $2.78 \%$ for cardoon. The biomasses samples were characterized following the NREL lap [14]. Cellulose and hemicellulose were calculated indirectly by measuring the concentration of glucose and $\mathrm{C} 5$ sugars through high performance liquid chromatography (HPLC) analysis using a Thermo Scientific Dionex Ultimate 3000 UHPLC after centrifugation and filtration of characterized samples through $0.22 \mu \mathrm{m}$ nylon filters. The monomeric sugars present in the liquid fraction were measured directly by HPLC. The oligomeric sugars were determined as the difference between the total monomeric sugars obtained after acid hydrolysis of the liquid fraction (in $4 \% w / w \mathrm{H} 2 \mathrm{SO} 4$ at $121^{\circ} \mathrm{C}$ for $1 \mathrm{~h}$ ) and the monomeric sugars measured in the liquid fraction before acid hydrolysis. The UHPLC system was equipped with a Bio-rad Aminex HPX-87H column and a ERC Refractomax 520 refractive index detector. The working conditions were $0.600 \mathrm{~mL} / \mathrm{min}$, at $50{ }^{\circ} \mathrm{C}$ and with $\mathrm{H} 2 \mathrm{SO} 40.01 \mathrm{~N}$ mobile phase.

\section{Results}

A sustainable and alternative energy source, in order to be preferred to fossil fuels, should be economically viable, environmentally friendly, provide energy security, reducing greenhouse emissions, not compete with food crops and biodiversity. Under this considerations, the characterization of residual biomasses will play an important role in bioenergy production. Discovering new sources of raw materials for the production of biofuels in a sustainable way is very important, and their characterization is crucial [15].

\subsection{Chemical Composition of Biomasses}

The cellulose, hemicellulose, acetyls, lignin and extractives content of each biomass sample were graphically reported with a bar chart in Figure 1 and in Table 2 were reported the values for each component for better visualizing the data. 


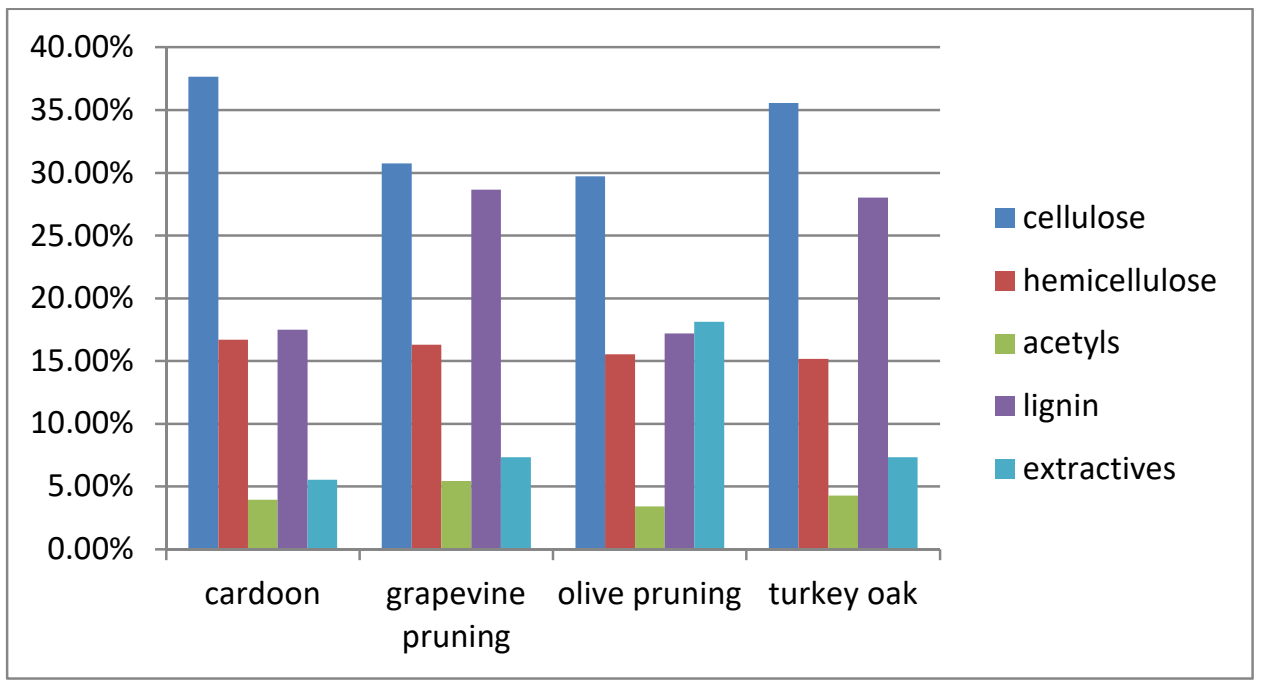

Figure 1. Chemical composition of each biomass.

Table 2. Chemical composition of each biomass.

\begin{tabular}{cccccc}
\hline & Cellulose & Hemicellulose & Acetyls & Lignin & Extractives \\
\hline Cardoon & $37.65 \%$ & $16.70 \%$ & $3.96 \%$ & $17.51 \%$ & $5.55 \%$ \\
Grapevine prunings & $30.70 \%$ & $16.32 \%$ & $5.43 \%$ & $28.67 \%$ & $7.33 \%$ \\
Olive prunings & $29.70 \%$ & $15.58 \%$ & $3.42 \%$ & $17.22 \%$ & $18.12 \%$ \\
River bank residues & $35.56 \%$ & $15.19 \%$ & $4.29 \%$ & $28.01 \%$ & $7.34 \%$ \\
\hline
\end{tabular}

The cellulose content of these biomasses, although slightly different between each type of biomass, is high in general, showing their validity for possible use in biofuel production. Cardoon shows the highest content in cellulose (37.65\%); other factors that make this biomass interesting is the low content of lignin and extractives and acetyls (3.96\%), although the last in particular could negatively affect further microbial processes. Other work on the production of bioethanol using cardon harvested in Spain, showed similar composition values [16]. Hemicellulose content is similar, around 15-16\%, in every considered biomass; this is due to the fact that all these biomasses are hardwood and arbustives. In case of herbaceous biomasses, hemicellulose content would have been higher [17]. The hemicellulose content is in major part hydrolyzed during pre-treatment process and recovered in liquid fraction, with the possibility of employment for other scope, like co-digestion for biogas production [18]. The acetyls content, that like previously mentioned could negatively affect the microbial fermentation, is low for each sample. The grapevine pruning and turkey oak show a higher content of lignin, equal to $28.67 \%$ and $28.01 \%$ respectively. the high content of lignin represent an obstacle for saccharification phase of bioethanol production, because don't make the cellulose easily accessible for the enzymes [16]. For what concerns extractives, which are all the impurities or chemical compounds that can be extracted with water and ethanol and could interfere with analytical procedure, the olive pruning shows a high percentage of these extractives. This is due to its intrinsic high concentration of polyphenols $(18.12 \%)$ that make this biomass not suitable for fermentation processes, as these molecules exhibit strong antioxidant and antimicrobial activities [19].

\subsection{Proximate and Ultimate Analysis Results}

The results of proximate analysis conducted on biomasses samples in terms of moisture content, volatile matter, ash and fixed carbon, along with their respective dry values, were reported in Table 3 and graphically in Figure 2, the graph allows for a more clear visualization of the differences among the biomasses. 
Table 3. TGA analysis results for each sample investigated.

\begin{tabular}{cccccccc}
\hline & Moisture & $\begin{array}{c}\text { Volatile } \\
\text { Matter }\end{array}$ & Ash & $\begin{array}{c}\text { Fixed } \\
\text { Carbon }\end{array}$ & $\begin{array}{c}\text { Dry Volatile } \\
\text { Matter }\end{array}$ & $\begin{array}{c}\text { Dry Ash } \\
\text { Dry Fixed } \\
\text { Carbon }\end{array}$ \\
\hline cardoon & $8.38 \%$ & $68.17 \%$ & $9.12 \%$ & $14.67 \%$ & $74.14 \%$ & $9.91 \%$ & $15.95 \%$ \\
grapevine pruning & $7.22 \%$ & $71.45 \%$ & $2.68 \%$ & $18.98 \%$ & $76.73 \%$ & $2.87 \%$ & $20.39 \%$ \\
olive pruning & $5.56 \%$ & $74.63 \%$ & $1.94 \%$ & $17.87 \%$ & $79.03 \%$ & $2.05 \%$ & $18.93 \%$ \\
River bank residues & $6.19 \%$ & $73.25 \%$ & $2.25 \%$ & $18.31 \%$ & $78.09 \%$ & $2.40 \%$ & $19.42 \%$ \\
\hline
\end{tabular}

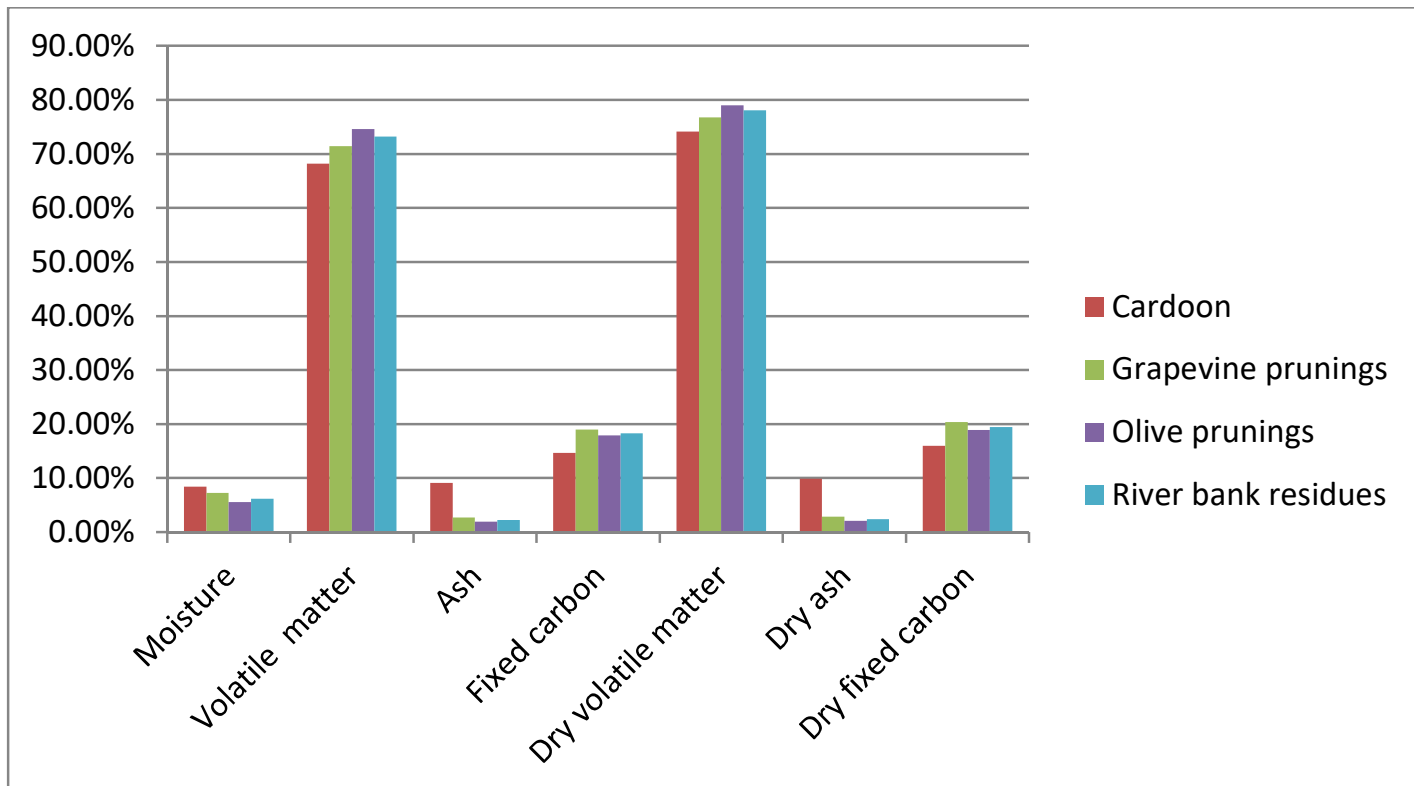

Figure 2. Graphical representation of proximate analysis conducted with TGA, in the graph are distinguished on a dry basis from those on the raw material.

The moisture content represents the quantity of water present in the biomass, expressed as a percentage of the raw material weight. High moisture content has a significantly lower carbon burn rate [20]. Among the biomasses examined in this work, the moisture content is very low and similar for each type of biomass [21]. The volatile matter of biomass is composed by condensable vapor and permanent gases (exclusive of water vapor) released when the biomass is heated to $925^{\circ} \mathrm{C}$ for few minutes. During this heating, the biomass decomposes into gases and solid matter is left out as char. The presence of volatile matter in biomass influences fuel reactivity, it has been observed that an increase in the volatile matter content of the biomasssample causes, as a general tendency, an increase in the peak temperature. The peak temperature is the point on the burning profile at which the rate of weight loss due to combustion is maximum. The burning profile peak temperature is usually taken as ameasure of the reactivity of the sample [22]. The volatile matter content is also an important parameter for evaluating anaerobic digestion for biogas production [21]. The olive pruning residues could be again reutilized as anaerobic digestion raw material. The ash content represents the amount of the solid, inorganic residue left after the complete burning of the biomass. It is an integral part of plant material with a wide range of elements. The primary components of biomass ash are oxides of silica, aluminium, iron, calcium, magnesium, titanium, sodium and potassium. For example, knowing the exact composition of the ashes of a biomass aids in predicting both its tendency to form deposits in the boiler components and the composition of the char produced during pyrolysis and gasification processes, which in turn also influence the combustion rate. The percentage and composition varies according to the type of biomass [15]. Cardoon shows an ash content equal to $9.12 \%$, greater than other samples, possessing an ash content of about 2-3\% due to perennial crops having more ash than wood crops. A factor which could influence ash content is soil contamination [23]. Fixed carbon is the solid combustible residue that remains after biomass is heated and volatile matter is expelled 
excluding the ash and moisture content [21]. The fixed carbon and volatile matter can influence the biological conversion of the fuel. Woody biomass has a much higher fixed carbon content as compared to arbustives and perennial crops. Cardoon indeed shows $14.67 \%$ of fixed carbon, diverging from other samples that present values around $18 \%$. Ultimate analysis, as shown in Figure 3, is mainly focused on carbon, hydrogen and nitrogen content. These elements are the major component of biomass and determine the fuel efficacy and the possible pollutant behavior [15]. Maximum carbon content was recorded in turkey oak with a value $47.63 \%$ and the minimum in the cardoon with $41.57 \%$, although the difference between the two is low. Both hydrogen and nitrogen contents were very small compared to carbon content. Hydrogen content is practically the same in each biomass as for nitrogen, with only olive pruning showing very low nitrogen content of about $1.28 \%$, the low nitrogen content results in a reduction of $\mathrm{NO}_{x}$ production during combustion [24].

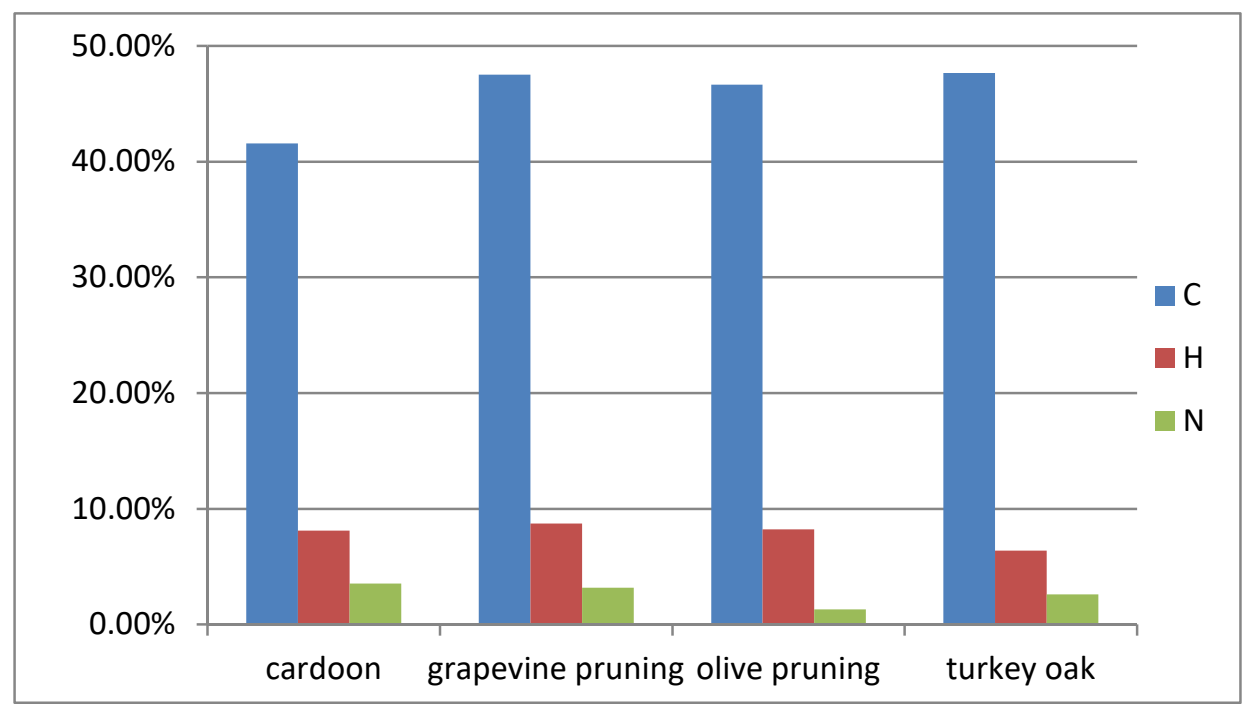

Figure 3. Ultimate analysis for the biomass samples.

The HHV of any fuel is the energy released per unit of mass per unit of volume of the fuel when it is completely burned. The HHV refers to the condition where water is condensed out of the combustion products and represents the gross calorific value. The HHV, which is another way to represent the energetic density of these biomasses, reported in Table 4, were calculated from the elemental composition on the basis of an empirical formula and expressed in MJ $/ \mathrm{kg}$. The HHV of a lignocellulosic fuel is a function of its lignin content, it can be compared the HHVs with the chemical composition data. The HHVs of these lignocellulosic feedstock increase with increase of their lignin contents, demonstrate that the HHV is highly correlated with lignin content [25]. The cardoon in fact shows the lowest HHV value (14.73), while the grapevine prunings and the turkey oak show the highest values among the biomasses investigated, (19.24) and (19.22) respectively.

Table 4. HHV expressed in MJ/kg for each biomass.

\begin{tabular}{cc}
\hline Sample & HHV (MJ/kg) \\
\hline Cardoon & 14.73 \\
Grapevine pruning & 19.24 \\
Olive pruning & 18.62 \\
Turkey oak & 19.22 \\
\hline
\end{tabular}

\subsection{Micro and Macro Nutrient Composition}

Table 5 shows the results of the ICP analyses performed on samples of every biomass studied in this work: 
Table 5. Macroelements analysed with ICP for each sample.

\begin{tabular}{ccccc}
\hline Element & \multicolumn{4}{c}{ Concentration $\mathbf{( m g} / \mathbf{k g})$} \\
\hline & Cardoon & Grapevine & Olive & Turkey Oak \\
\hline $\mathrm{P}$ & $11,387.7$ & $21,159.5$ & $12,752.7$ & 437.278 \\
$\mathrm{Mg}$ & 7335.04 & $26,909.6$ & 8665.55 & 493.107 \\
$\mathrm{Na}$ & 51,214 & 510,229 & 1503.85 & 0.57956 \\
$\mathrm{~K}$ & 186,355 & $85,429.5$ & $41,801.30$ & 3145.38 \\
$\mathrm{Ca}$ & 182,968 & 150,563 & 110,200 & 6654.87 \\
$\mathrm{Fe}$ & 263,604 & 8161.5 & 5237.33 & 111.909 \\
$\mathrm{Cu}$ & 445,788 & 458,507 & 131,914 & 2.94479 \\
$\mathrm{Al}$ & 3323.22 & $11,476.9$ & 729,483 & 91.1731 \\
\hline
\end{tabular}

ICP measurements were done with two objectives in mind; first, in order to assess each biomass' composition in terms of the most common micro- and macro- nutrients to determine the suitability of the biomass in thermal processes; during combustion, metals present in the biomass form reactive species which could corrode and degrade the mechanical parts of the machine [15]. It is evident how biomasses with low concentration of metals are to be preferred for this type of application. The micro nutrient concentration is correlated to the age of the plants, meaning that older plants exhibit higher concentrations of these elements [26]. For a sustainable energy system based on biomass, the nutrient substances in the ash should be recycled to the forest. The fly ash from boilers may contain high amount of unburnt carbon and not suitable for direct recycling. The high level of unburnt carbon not reflect only the inefficiency of boiler but reduce the ash stabilization and increase the volume of fly produced [26]. To enable recycling, the boiler combustion efficiency must be improved. From the collected data, high concentration of all of the investigated species suggest the possibility of employing all the considered biomasses in biogas production processes, while instead use as a fuel should be avoided, unless very efficient plants are used.

\section{Conclusions}

The first activities of the "Biocheaper" project were performed through the selection and collection of four lignocellulosic biomass typologies and the characterization of the samples to determine their possible applications in small-scale energy plants. The aim of the project is the efficient retrofitting of existing old plants in combination with the reutilization of agro-industrial residues. With this in mind, the complete characterization of the local biomasses is a crucial information to obtain in order to proceed on this way. All the selected biomasses showed concentrations of ashes around $2 \%$, but cardoon residues showed more than $9 \%$. The higher ash content and the higher moisture content are negative aspects to be considered for small scale biomass boilers supply. Higher heating values are also similar between samples and around $19 \mathrm{MJ} / \mathrm{kg}$, except for cardoon which shows approximately $15 \mathrm{MJ} / \mathrm{kg}$, lower than the others, data in correlation with its lowest lignin content. In light of these considerations, it can be said that cardoon is not recommended as a fuel for small energy production plants, but shows interesting value for bio-ethanol production or other bio-product. The concentrations of the micro- and macro-elements analyzed are compatible with the use as biofuels in small-scale applications. In the next stages of the Biocheaper project, the collected data will be used as preliminary information to carry out the fluidodynamics simulations and the test performances into biomass boilers.

Author Contributions: A.B. and A.P., carried out analysis on the biomasses, G.C. designed the study and drafted the manuscript, V.C., A.F. and A.N. drafted the manuscript, and F.C. designed the study and supervised the research. All authors read and approved the manuscript.

Funding: This study was funded by the Italian Ministry for Education and Scientific Research (MIUR) through the project: "BIOmasses Circular Holistic Economy Approach to EneRgy equipment (BIO-CHEAPER) (Projeckt prot. PRIN 2017_20175TXJER). 
Acknowledgments: We would like to thank Matrica for supplying the cardoon biomass and Cantine Giorgio Lungarotti for supplying the grapevine prunings used in the experimentation.

Conflicts of Interest: The authors declare no conflict of interest.

\section{References}

1. Patel, M.; Zhang, X.; Kumar, A. Techno-economic and life cycle assessment on lignocellulosic biomass thermochemical conversion technologies: A review. Renew. Sustain. Energy Rev. 2016, 53, 1486-1499. [CrossRef]

2. Cotana, F.; Cavalaglio, G.; Coccia, V.; Petrozzi, A. Energy opportunities from lignocellulosic biomass for a biorefinery case study. Energies 2016, 9, 748. [CrossRef]

3. Pedrazzi, S.; Allesina, G.; Morselli, N.; Puglia, M.; Barbieri, L.; Lancellotti, I.; Ceotto, E.; Cappelli, G.A.; Ginaldi, F.; Giorgini, L. The energetic recover of biomass from river maintenance: The REBAF project. In Proceedings of the 25th European Biomass Conference and Exhibition, Stockholm, Sweden, 12-15 July 2017; pp. 12-15.

4. Lgs, D. 152/2006. Decreto Legislativo; Istituto Poligrafico e Zecca dello Stato: Rome, Italy, 2006.

5. Vakalis, S.; Baratieri, M. Calculating the overall efficiency of polygeneration plants-introducing an integrated thermodynamic decision tool for biomass gasification. In Proceedings of the Symbiosis International Conference 2014, Athens, Greece, 19-21 June 2014.

6. Maraver, D.; Sin, A.; Royo, J.; Sebastián, F. Assessment of CCHP systems based on biomass combustion for small-scale applications through a review of the technology and analysis of energy efficiency parameters. Appl. Energy 2013, 102, 1303-1313. [CrossRef]

7. Torquati, B.; Marino, D.; Venanzi, S.; Porceddu, P.; Chiorri, M. Using tree crop pruning residues for energy purposes: A spatial analysis and an evaluation of the economic and environmental sustainability. Biomass Bioenergy 2016, 95, 124-131. [CrossRef]

8. Cavalaglio, G.; Cotana, S. Recovery of vineyards pruning residues in an agro-energetic chain. Peach 2007, 2, 6.

9. Angelini, L.G.; Ceccarini, L.; o Di Nasso, N.N.; Bonari, E. Long-term evaluation of biomass production and quality of two cardoon (Cynara cardunculus L.) cultivars for energy use. Biomass Bioenergy 2009, 33, 810-816. [CrossRef]

10. Hames, B.; Ruiz, R.; Scarlata, C.; Sluiter, A.; Sluiter, J.; Templeton, D. Preparation of samples for compositional analysis. Lab. Anal. Proced. (LAP) 2008, 1617, 1-10.

11. ASTM International. D5373-93 (1997): Standard Methods for Instrumental Determination of Carbon, Hydrogen, and Nitrogen in Laboratory Samples of Coal and Coke; ASTM International: West Conshohocken, PA, USA, 1993.

12. Zhang, L.; Xu, C.C.; Champagne, P. Energy recovery from secondary pulp/paper-mill sludge and sewage sludge with supercritical water treatment. Bioresour. Technol. 2010, 101, 2713-2721. [CrossRef] [PubMed]

13. Telmo, C.; Lousada, J.; Moreira, N. Proximate analysis, backwards stepwise regression between gross calorific value, ultimate and chemical analysis of wood. Bioresour. Technol. 2010, 101, 3808-3815. [CrossRef] [PubMed]

14. Sluiter, A.; Hames, B.; Ruiz, R.; Scarlata, C.; Sluiter, J.; Templeton, D.; Crocker, D. Determination of structural carbohydrates and lignin in biomass. Lab. Anal. Proced. 2008, 1617, 1-16.

15. Singh, Y.D.; Mahanta, P.; Bora, U. Comprehensive characterization of lignocellulosic biomass through proximate, ultimate and compositional analysis for bioenergy production. Renew. Energy 2017, 103, 490-500. [CrossRef]

16. Vergara, P.; Ladero, M.; García-Ochoa, F.; Villar, J.C. Pre-treatment of corn stover, Cynara cardunculus L. stems and wheat straw by ethanol-water and diluted sulfuric acid: Comparison under different energy input conditions. Bioresour. Technol. 2018, 270, 449-456. [CrossRef] [PubMed]

17. Iyer, P.V.; Wu, Z.-W.; Kim, S.B.; Lee, Y.Y. Ammonia recycled percolation process for pretreatment of herbaceous biomass. Appl. Biochem. Biotechnol. 1996, 57, 121. [CrossRef]

18. Dos Santos, L.C.; Adarme, O.F.H.; Baêta, B.E.L.; Gurgel, L.V.A.; de Aquino, S.F. Production of biogas (methane and hydrogen) from anaerobic digestion of hemicellulosic hydrolysate generated in the oxidative pretreatment of coffee husks. Bioresour. Technol. 2018, 263, 601-612. [CrossRef]

19. Conde, E.; Cara, C.; Moure, A.; Ruiz, E.; Castro, E.; Domínguez, H. Antioxidant activity of the phenolic compounds released by hydrothermal treatments of olive tree pruning. Food Chem. 2009, 114, 806-812. [CrossRef] 
20. Grandesso, E.; Gullett, B.; Touati, A.; Tabor, D. Effect of moisture, charge size, and chlorine concentration on PCDD/F emissions from simulated open burning of forest biomass. Environ. Sci. Technol. 2011, 45, 3887-3894. [CrossRef]

21. Cai, J.; He, Y.; Yu, X.; Banks, S.W.; Yang, Y.; Zhang, X.; Yu, Y.; Liu, R.; Bridgwater, A.V. Review of physicochemical properties and analytical characterization of lignocellulosic biomass. Renew. Sustain. Energy Rev. 2017, 76, 309-322. [CrossRef]

22. Haykırı-Açma, H. Combustion characteristics of different biomass materials. Energy Convers. Manag. 2003, 44, 155-162. [CrossRef]

23. Coulson, M.; Dahl, J.; Gansekoele, E.; Bridgwater, A.; Obernberger, I.; Van de Beld, L. Ash characteristics of perennial energy crops and their influence on thermal processing. In Proceedings of the 2nd World Biomass Conference, Rome, Italy, 10-14 May 2004; pp. 359-362.

24. Thomas, K.M. The release of nitrogen oxides during char combustion. Fuel 1997, 76, 457-473. [CrossRef]

25. Demirbas, A. Relationships between Heating Value and Lignin, Moisture, Ash and Extractive Contents of Biomass Fuels. Energy Explor. Exploit. 2002, 20, 105-111. [CrossRef]

26. Demirbaş, A. Heavy metal contents of fly ashes from selected biomass samples. Energy Sources 2005, 27, 1269-1276. [CrossRef]

(C) 2020 by the authors. Licensee MDPI, Basel, Switzerland. This article is an open access article distributed under the terms and conditions of the Creative Commons Attribution (CC BY) license (http://creativecommons.org/licenses/by/4.0/). 